\title{
Histopathology of benign non-palpable breast lesions identified by mammography
}

\author{
NICOLA J BARNARD,* B D GEORGE,* A K TUCKER, $†$ O J A GILMORE \\ From the Departments of *Pathology, $\uparrow$ Radiology, and $\ddagger$ Surgery, St Bartholomew's Hospital, London
}

SUMMARY Over four years the histological features of benign breast diseases, diagnosed after biopsy of non-palpable mammographic abnormalities, were reviewed and correlated with the mammographic appearances. The histological features were compared with those from all other benign biopsy specimens taken during the same period. The incidence of sclerosing adenosis and microcalcifications was considerably higher in the group of non-palpable mammographic lesions; fibrous disease of the breast and radial scar (infiltrating epitheliosis) were also more common. There was no difference in the incidence of epithelial hyperplasia between the two groups. Correlation with the mammographic appearances showed that microcalcification was most often associated with blunt duct adenosis and that stromal distortion or masses were most often caused by fibrous disease.

The detection of non-palpable breast carcinomas by mammography permits earlier diagnosis ${ }^{1-3}$ and reduces mortality. ${ }^{4-7}$ Excision of non-palpable lesions may be performed by various techniques including wide excision, the use of skin markers, radio-opaque dyes and needle localisation. We have found that the use of a guide wire is accurate and reliable. Many biopsies performed on the basis of mammographic changes, however, are due to benign breast disease. As the use of mammography becomes more widespread the number of benign biopsy specimens will increase and histopathologists should be aware of the spectrum of disorders responsible for non-palpable mammographic abnormalities. In this study the pathology of all benign biopsy specimens of non-palpable mammographic lesions was reviewed and related to the mammographic appearances. The histology of palpable and non-palpable benign breast abnormalities was also compared.

\section{Material and methods}

All women over 30 years of age (range 30-89) presenting to the breast clinic of this hospital are offered mammography after clinical examination. During the four years between June 1982 and June 198654 mammographic abnormalities suspicious of carcinoma were detected, which did not correspond

Accepted for publication 9 June 1987 to palpable masses despite careful clinical examination. Preoperative localisation of these lesions was achieved with a hooked guide wire inserted under radiographic control, using local anaesthetic, preferably less than 24 hours before surgery (fig 1). The site and volume of breast tissue vital for excision was calculated from these films and subsequently excised under general anaesthesia. Our policy was to embed all breast tissue around the distal two thirds of the guide wire for histological examination. If the guide wire had been removed or dislodged then small specimens were totally embedded. Larger specimens were carefully inspected macroscopically and at least two thirds of the breast tissue was routinely processed for histological examination. Twenty four of the 54 guide wire biopsy specimens were malignant on histological examination.

In this study the histological findings in the $\mathbf{3 0}$ cases due to benign breast disease were reviewed and related to the mammographic abnormalities seenthat is, microcalcifications and stromal distortion and spiculation. In addition, the histological findings were compared with those of all other benign breast biopsy specimens received during the same period. The guide wire biopsy specimens showing fibrocystic disease were compared with age matched cases of fibrocystic disease diagnosed after conventional biopsy of palpable masses. The features were recorded (table 1) and a comparison between palpable and nonpalpable lesions was made. 


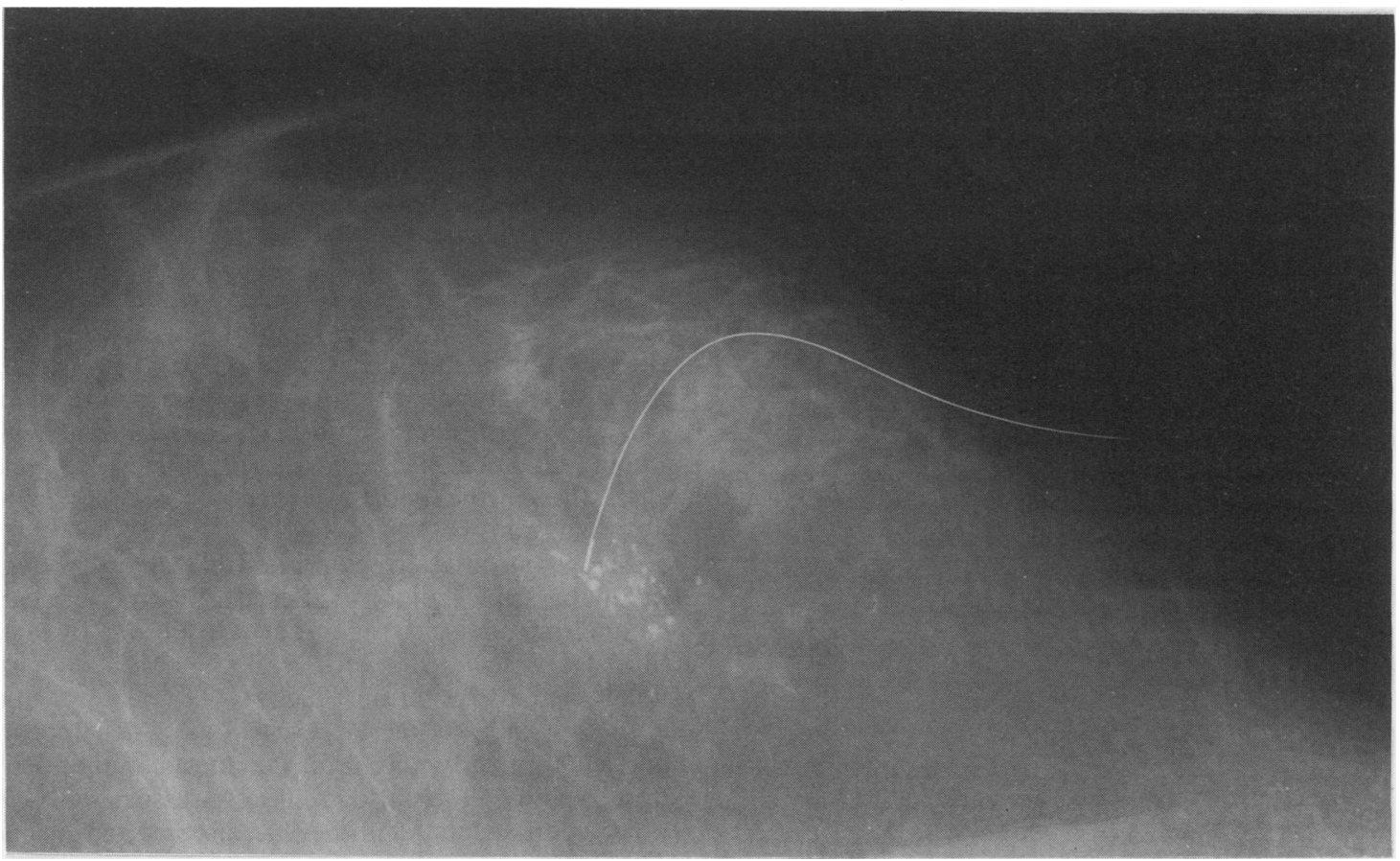

Fig 1 Mammogram showing hooked guide wire inserted close to suspicious areas of calcification.

\section{Results}

Two hundred and twenty four histologically benign breast biopsies were performed in women over 30 years of age. Thirty of these were excised for nonpalpable lesions which were mammographically suspicious of malignancy. Table 2 lists the histopathological diagnoses.

\section{Table 1 Definitions of terms used ${ }^{26}$}

Microcalcification Small irregular particles of calcium seen in microscopic sections

Cyst

Blunt duct adenosis

Usually a lobular derived structure due to dilatation and coalescence of acini Lobular hypertrophy with associated specialised stroma

Sclerosing adenosis Lobular proliferation in which the acini acquire distorted infiltrative margins

Epitheliosis

Benign non-papillary epithelial proliferation within the mammary glandular tree

\section{Apocrine} metaplasia

Duct ectasia

Epithelial cells resembling those seen in normal apocrine sweat glands

Dilatation affecting major subareolar ducts, usually with surrounding fibrosis

Radial scar

A discrete stellate fibro-elastic and epithelial lesion

Fibrous disease

Breast tissue containing irregular zones of fibrosis extensively replacing epithelial elements
Table 3 shows the comparison between the 23 cases of fibrocystic disease (including radial scar) diagnosed following biopsy of non-palpable mammographic lesions and age matched controls. Microcalcification and sclerosing adenosis were more common in the non-palpable group, fibrous disease of the breast and radial scar (infiltrating epitheliosis) were also observed more often, although this difference was not significant.

Table 4 shows the correlation of histological and mammographic findings. The commonest site of

Table 2 Histological diagnoses of benign breast disorders in palpable and non-palpable groups

\begin{tabular}{lcc}
\hline & $\begin{array}{l}\text { Non-palpable } \\
\text { mammographic } \\
\text { lesions }\end{array}$ & $\begin{array}{l}\text { Palpable } \\
\text { breast } \\
\text { lesions }\end{array}$ \\
\hline Fiagnosis & 23 & 110 \\
$\begin{array}{l}\text { (Radial scar)* } \\
\text { Fibrous disease }\end{array}$ & $(2)$ & 1 \\
Fibroadenoma & 4 & 62 \\
Cyst & 1 & 5 \\
Duct papilloma & & 7 \\
Fat necrosis & 2 & 4 \\
Normal breast & 30 & 5 \\
Total No of cases & 304 \\
\hline
\end{tabular}

*(Radial scar included in fibrocystic disease complex). 
Table 3 Comparison of features of fibrocystic disease inpalpable and non-palpable groups

\begin{tabular}{lll}
\hline $\begin{array}{l}\text { Feature of } \\
\text { fibrocystic } \\
\text { disease }\end{array}$ & $\begin{array}{l}\text { Non-palpable } \\
\text { fibrocystic } \\
\text { disease }\end{array}$ & $\begin{array}{l}\text { Palpable } \\
\text { fibrocystic } \\
\text { disease }\end{array}$ \\
\hline Microcalcification & 17 & $4^{*}$ \\
Cyst & 15 & 19 \\
Blunt duct adenosis & 8 & 12 \\
Sclerosing adenosis & 11 & $4^{*}$ \\
Epitheliosis & 9 & 11 \\
Apocrine metaplasia & 13 & 12 \\
Duct ectasia & 6 & 8 \\
\hline
\end{tabular}

${ }^{*} p<0.05 ; 23$ cases in each group.

Table 4 Correlation of histological and mammographic findings

\begin{tabular}{ll}
\hline Major histological site of: & No of cases \\
\hline Microcalcification: & \\
Normal/atrophic lobules & 4 \\
Blunt duct adenosis & 8 \\
Sclerosing adenosis & 3 \\
Cysts & 3 \\
Fibroadenoma & 1 \\
Radial scar & 1 \\
Stromal mass or irregularity: & \\
Fibrous disease & 4 \\
Cysts and fibrosis & 2 \\
Sclerosing adenosis & 2 \\
Blunt duct adenosis and fibrosis & 1 \\
Radial scar & 1 \\
\hline
\end{tabular}

microcalcification was in areas of blunt duct adenosis and the most common cause of irregular stromal distortion was fibrous disease.

\section{Discussion}

Impalpable mammographic lesions are excised in an attempt to detect early breast carcinoma. ${ }^{1-7}$ Mammography detects abnormalities on the basis of microcalcification or by detection of changes in tissue density or architecture, ${ }^{8}$ thus the histological changes seen most commonly in biopsy specimens of impalpable lesions will be those associated with calcification or fibrosis. Inevitably, biopsies will be performed because of benign disease. In this series 30 of 54 biopsy specimens were histologically benign $(55 \%)$.

Calcification occurs in both malignant and benign breast disease and it was initially held that the pattern of calcification seen on mammography in benign lesions could be distinguished from that of carcinoma. ${ }^{910}$ It has since become clear that small clusters of calcification may be present in benign disorders in a pattern indistinguishable from that seen in carcinoma. ${ }^{1-14}$ They have been observed in sclerosing adenosis, apocrine metaplasia, blunt duct adenosis, cysts, and in the stroma of benign breast tissue. ${ }^{1215}$ Azzopardi states that calcification is not a feature of ductal epithelial hyperplasia (epitheliosis) ${ }^{16}$ although others have noted its presence. In one series of 1484 breast biopsy specimens, calcification was observed in $62 \%$ of malignant tumours, but only $23 \%$ of benign lesions. ${ }^{11}$

In this study, the most common site of benign microcalcification was in areas of blunt duct adenosis, often within inspissated secretion, but calcification was also commonly seen in areas of sclerosing adenosis and apocrine cysts (fig 2). One radial scar containing microcalcification was identified. In some cases the calcifications appeared to be confined to atrophic acini (fig 2).

Benign stromal irregularities that may produce mammographic abnormalities suspicious of carcinoma include sclerosing adenosis, fibrous disease, fibrosis associated with duct ectasia, cysts, inflammatory conditions such as fat necrosis and abscesses, and postoperative scarring. ${ }^{17}$ Such appearances in this study were produced most commonly by fibrous disease, but also by fibrosis associated with other components of fibrocystic disease, and in one case by a radial scar.

When the histology of non-palpable cases of fibrocystic disease was compared with that of the palpable cases, there was the expected excess of microcalcification in the non-palpable cases. Sclerosing adenosis was also identified more commonly in this group, probably because it often contains microcalcification or produces stromal distortion.

Although the numbers were small, both radial scars and fibrous disease seemed to be more common in the non-palpable group. Radial scar consists of a central fibroelastic core with radiating arms of ducts and lobules which may exhibit epithelial hyperplasia, cyst formation, and apocrine metaplasia. ${ }^{18}$ The resulting stellate lesion, often containing microcalcification, resembles carcinoma both grossly and mammographically, and these lesions will probably be identified in increasing numbers with the widespread use of mammography. Some authors suggest that radial scar is the site of origin of most carcinomas. ${ }^{19}$ This is regarded, however, as benign by most authors, and follow up studies have failed to show an increased incidence of carcinoma. ${ }^{2021}$ Radial scar is a small lesion. Wellings and Alpers ${ }^{18}$ state a size range of $5-10 \mathrm{~mm}$ in diameter, while Nielson et al $^{22}$ report that $75 \%$ of their cases were less than $7 \mathrm{~mm}$ in diameter and none exceeded $13 \mathrm{~mm}$. It is therefore understandable that it is more likely to produce a non-palpable mammographic lesion rather than a palpable mass.

Fibrous disease is a disputed pathological entity, 


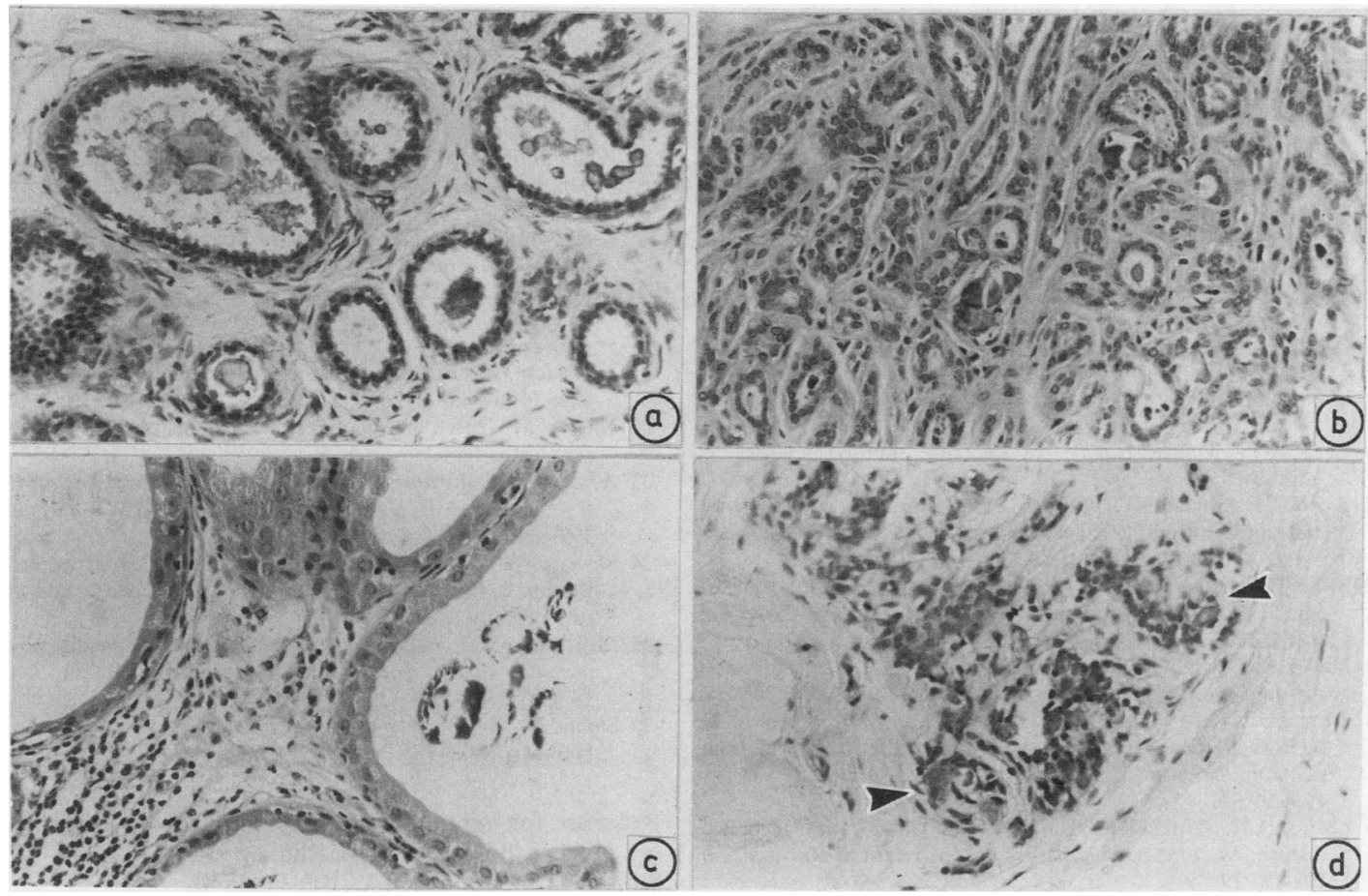

Fig 2 Microcalcification in blunt duct adenosis (a), sclerosing adenosis (b), apocrine cysts (c) and normal lobule (d).

which Azzopardi ${ }^{23}$ suggests, is an extreme of normal involutionary changes in the breast. Fibrous disease does, however, represent a real clinical entity, ${ }^{24}$ and this study suggests that it is also a cause of suspicious mammographic abnormalities.

In two cases the mammogram showed irregular densities which were histologically an organising haematoma and an area of fat necrosis. The latter is notorious for mimicking carcinoma clinically and radiologically but usually presents with a palpable mass. In one case an irregular mass with microcalcification was noted mammographically and proved to be a sclerosed fibroadenoma. This case was somewhat unusual in that fibroadenomas are more likely to contain macrocalcifications (radiologically greater than $1 \mathrm{~mm}$ in diameter). The sclerosis of the lesion probably accounted for its irregular outline.

Moskowitz has suggested that biopsies which prove to be benign, performed on the basis of abnormal mammograms, show an increased incidence of epithelial proliferation and atypia, ${ }^{25}$ but in this study there was no excess of epithelial hyperplasia (epitheliosis) in the non-palpable group of biopsy specimens. As calcification is not a usual feature of either ductal or lobular epithelial hyperplasia ${ }^{16}$ this will probably not be identified by mammography unless there is associated stromal distortion.

Excision of non-palpable mammographic lesions plays a major part in the detection of early breast carcinoma. We have reported the spectrum of benign disorders seen in tissue excised following the detection of non-palpable mammographic abnormalities. Sclerosing adenosis, radial scar, and fibrous disease of the breast seem to be important benign causes of suspicious mammographic lesions in the absence of a palpable mass.

We thank Dr David Levison for encouragement and advice and Mrs Helen Sterba and Mrs Rosemary Foong for typing the manuscript.

\section{References}

1 Chetty U, Kirkpatrick AE, Anderson TL, et al. Localisation and excision of occult breast lesions. Br J Surg 1983;70:607-10.

2 Patchesfshy AS, Shaher GS, Schwartz GF, Feig RE, Nerlinger RE. The pathology of breast cancer detected by mass population screening. Cancer 1977;40:1659-70.

3 Gibb NM. Comparative study of the histopathology of breast cancer in a screened and unscreened population investigated by mammography. Histopathology 1985;9:1307-18. 
4 Shapiro S, Strax P, Venet L. Periodic breast cancer screening in reducing mortality from breast cancer. JAMA 1971;215:1777-85.

5 Shapiro S, Venet W, Strax P, Venet L, Roeser R. Ten to fourteen year effect of screening on breast cancer mortality. JNCI 1982;69:349-55.

6 Tabar L, Fagerberg CJG, Gad A, et al. Reduction in mortality from breast cancer after mass screening with mammography. Lancet 1985; i:829-32.

7 Hutchinson J, Tucker AK. Breast screening results from a healthy working population. Clin Oncol 1984;10:123-8.

8 Tabar L, Dean PB. Teaching atlas of mammography. 2nd ed. Stuttgart: Georg Thieme Verlag, 1985.

9 Leborgne $R$. Diagnosis of tumors of the breast by simple roentgenography: calcifications in carcinoma. Am $J$ Roent 1951;65:1-11.

10 Egan RL. Mammography. Springfield, Illinois: Charles C Thomas, 1964.

11 Koehl RH, Snyder RE, Hutter RPV, Foote FW. The incidence and significance of calcifications within operative breast specimens. Am J Clin Pathol 1970;53:3-14.

12 Millis RR, Davis R, Stacy AJ. The detection and significance of calcifications in the breast: a radiological and pathological study. Br J Radiol 1976;49:12-26.

13 Powell RW, McSweeney MB, Wilson CE. X-ray calcifications as the only basis for breast biopsy. Ann Surg 1983;197:555-9.

14 Tinnemans JGM, Wobbes T, Lubbers E-JC, vandar Sluis RF, de Boer HHM. The significance of microcalcifications without palpable mass in the diagnosis of breast cancer. Surgery 1986;99:652-7.

15 Levitan LH, Witten DM, Harrison EG. Calcification in breast disease. Mammographic-pathologic correlation. Am J Roent 1964;92:29-39.
16 Azzopardi JG. Epitheliosis and carcinoma. In: Azzopardi JG, ed. Problems in breast pathology. Philadelphia: WB Saunders, 1979:125-6.

17 Millis RR. Mammography. In: Azzopardi JG, ed. Problems in breast pathology. Philadelphia: WB Saunders, 1979:437-59.

18 Wellings SR, Alpers CE. Subgross pathological features and incidence of radial scars in the breast. Hum Pathol 1984;15:475-9.

19 Linell F. Ljungber O, Anderson I. Breast carcinoma: aspects of early stages, progression and related problems. Acta Pathol Microbiol Immunol Scand (A) 1980;272:1-233.

20 Fenoglio $\mathbf{C}$, Lattes $\mathbf{R}$. Sclerosing papillary proliferations in the female breast: a benign lesion often mistaken for carcinoma. Cancer 1974;33:691-700.

21 Anderson JA, Gram JB. Radial scar in the female breast: a long term follow-up study of 32 cases. Cancer 1984;53:2557-60.

22 Nielsen M, Jensen J, Anderson JA. An autopsy study of radial scar in the female breast. Histopathology 1985;9:287-95.

23 Azzopardi JG. Fibrosis of the breast. In: Azzopardi JG, ed. Problems in breast pathology. Philadelphia: WB Saunders, 1979:89-90.

24 Stewart FW. Tumours of the breast. Atlas of tumour pathology. Section 9, Fascicle 34. Washington, DC: Armed Forces Institute of Pathology, 1950:99.

25 Moskowitz M, Pemmaraju S, Fidler JA, et al. On the diagnosis of minimal breast cancer in a screened population. Cancer 1976;37:2543-52.

26 Sloane JP. Biopsy pathology of the breast. London: Chapman and Hall Medical, 1985.

Requests for reprints to: Dr N J Barnard, Department of Histopathology, St Bartholomew's Hospital, West Smithfield, London EC1A 7BE, England. 